\title{
Effect of transient flux compensation control on fault ride through of doubly fed induction generator wind turbine
}

\author{
A.S. Mäkinen, H. Tuusa \\ Department of Electrical Energy Engineering \\ Tampere University of Technology \\ Korkeakoulunkatu 3, P.O. Box 692, FI-33101 Tampere, Finland \\ Phone/Fax number: +358331152380, e-mail: anssi.makinen@tut.fi, heikki.tuusa@tut.fi
}

\begin{abstract}
The fault ride through (FRT) of doubly fed induction generator (DFIG) is studied in this paper. Two different FRT strategies are compared. First strategy uses only active crowbar to protect the turbine and the second strategy uses transient flux compensation in addition to the crowbar. Simulations are carried out using Matlab/Simulink. The aim of the study is to reveal how the transient flux compensation improves the operation of DFIG during a fault. If the transient flux is removed the DFIG is controllable during a fault and the reactive power injection to the grid can be maximized. This is an important aspect since the latest grid codes insist that wind turbines should be able to inject reactive power during a fault in order to support the depressed grid voltage. Thus, this paper proposes that after a fault it is reasonable to use the current capacity of rotor side converter to remove the transient flux. This leads to better performance of wind turbine, improved power quality and maximized voltage support.
\end{abstract}

\section{Key words}

DFIG (doubly fed induction generator), FRT (fault ride through), voltage dip, transient flux

\section{Introduction}

The global warming, air pollution and the shortfall of fossil energy sources have increased the interest towards the generation of electrical energy from renewable energy sources. Thus, the number of wind turbines installed to the grid has grown dramatically in recent years. According to the World Wind Energy Association (WWEA), the global wind power capacity had increased to $159.2 \mathrm{GW}$ by the end of 2009.[1] Hence, the penetration of wind generation has increased in many areas to a significant level. In such areas, power system operators have created grid codes which demand the wind turbines to be able to endure deep voltage dips in order to ensure power system stability. Grid codes include specifications that determine the requirements for the operation of generation units during disturbances. These specifications are known as the fault ride through (FRT) requirements.
As an example, E.ON Nezt grid codes regarding symmetrical faults are illustrated in Figs. 1a and 1b. [2] The wind turbines are not allowed to disconnect from the grid if the grid voltage is over the red line in Fig. 1a. In addition, the wind turbines should be able to inject reactive power to the grid in order to support the grid voltage. It can be seen in Fig. $1 \mathrm{~b}$ that wind turbines should inject a nominal value of reactive current if the voltage is lower than $50 \%$ of the nominal value. [2]

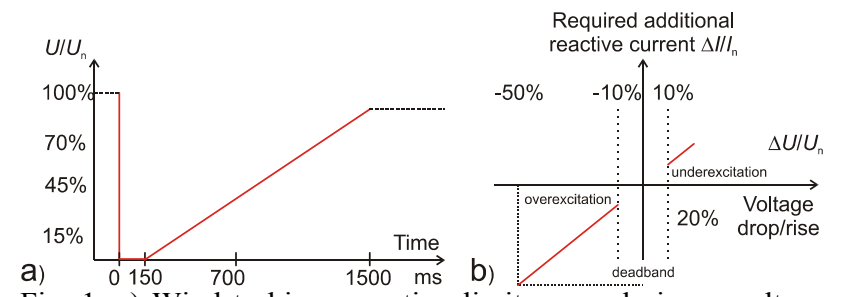

Fig. 1. a) Wind turbine operation limit curve during a voltage dip. b) Voltage support of wind turbine during a fault. [2]

The use of doubly-fed induction generators (DFIG) in variable speed wind turbines has been popular since the size and costs of the needed power electronic components are smaller compared to full power converter design. This fact leads also to smaller losses. However, the behaviour of the DFIG concept during grid voltage dip is problematic since the induction generator generates high voltages and currents to the rotor side as a result of the dip.

\section{A. Behaviour of DFIG during symmetrical voltage dip}

The amplitude of the rotating magnetic flux of DFIG is proportional to the stator voltage. A voltage dip in stator terminals decreases the amplitude of the rotating flux of the generator instantaneously. However, the total flux cannot change instantaneously. The difference between total flux and rotating flux is called a transient flux or a natural flux as defined by Lopez et al. [3]. The transient flux is not rotating and it appears only if there is a sudden step in the stator voltage. In addition, the transient flux gets its maximum value at the beginning of the voltage step. 
The induced voltage to the DFIG rotor is proportional to the stator to rotor turns ratio of the generator and angular slip frequency i.e., the difference between the synchronous angular frequency of the flux and the rotor electrical angular speed. Typical slip range of the DFIG drive varies between $\pm 30 \%$ of the synchronous angular frequency. Since the synchronous angular frequency of the transient flux is zero the angular slip frequency corresponds to the speed of the generator rotor. Thus, the transient flux creates very high rotor voltages.

The maximum attainable voltage of the rotor side converter (RSC) is limited by the DC-link voltage. A deep network voltage dip induces higher voltages to the rotor circuit than the RSC can generate from the DC-link voltage. In other words, the RSC cannot control the currents in the rotor circuit, nor can the currents be limited. This leads to high currents in the rotor circuit which can damage both the power electronic switches, i.e., IGBT, and the diodes that are connected anti parallel with the switches. If the IGBTs are switched off in order to protect them against over current, the current flow will continue to the DC-link through the diodes. This will, in turn, increase the DC-link voltage to an intolerable level. The DC-link capacitor may be damaged without any protective measures.

Typically, the RSC is disconnected from the rotor circuit after a voltage dip and a crowbar is connected the rotor circuit. A crowbar is an additional set of resistors that are used during a fault in order to decrease the rotor current. In [4], the crowbar is under operation as long as the rotor current has decreased to zero.

\section{B. Compensation of transient flux}

Xiang et. al. [5] propose a method where RSC generates rotor currents that oppose DC and negative sequence components of the stator flux linkage during a fault. The purpose is to cancel the transient flux in order to avoid rotor over voltage and RSC saturation. If the RSC saturation can be avoided the currents in the rotor circuit can be controlled and limited during the fault which stands for successful FRT without using any external devices, such as a crowbar.

Lopez et. al. [6] uses also currents that oppose DC and negative sequence components of the stator flux linkage. They define these currents as demagnetizing currents. However, they also point out that the amount of demagnetizing current needed to cancel the transient flux is very high. Thus, the RSC should be over dimensioned in order to have a large current capacity. It should be noted, however, that the main advantage of a DFIG concept is small dimensioned converters. Instead of over dimensioning the FRT process in [6] relies on the combination of crowbar protection and demagnetizing current injection. After a voltage dip, the crowbar is connected to the rotor circuit in order to reduce the rotor current and the RSC is disconnected. After the current is reduced lower than the current capability of the RSC the crowbar is disconnected and the RSC is activated again and it starts to feed demagnetizing current to the rotor circuit. Also, the RSC starts to feed reactive power to the network. In both [5] and [6], the operation of a grid side converter (GSC) is not taken into account.

In this paper, the effect of transient flux compensation control i.e., demagnetizing current injection during a fault is investigated. A comparison of two FRT strategies is made. The first FRT strategy uses only the active crowbar to protect the turbine and the second strategy uses transient flux compensation in addition to the crowbar. In both simulation cases, the GSC feeds reactive power to the grid during a voltage dip. Simulation results indicate that control system variables show much steadier behaviour when transient flux is compensated. This leads to better power quality and improved utilization of the current capacity of the RSC. Thus, it is possible to maximize the reactive power injection of the DFIG during a fault.

\section{System modeling}

The space-vector based equivalent circuit of the modelled DFIG is presented in Fig. 2. The stator of the generator is directly connected to the grid while the rotor circuit is connected to the grid via frequency converter. Variables with superscript " are reduced to the stator. The transformer describes the rotor to stator turns ratio of the generator.

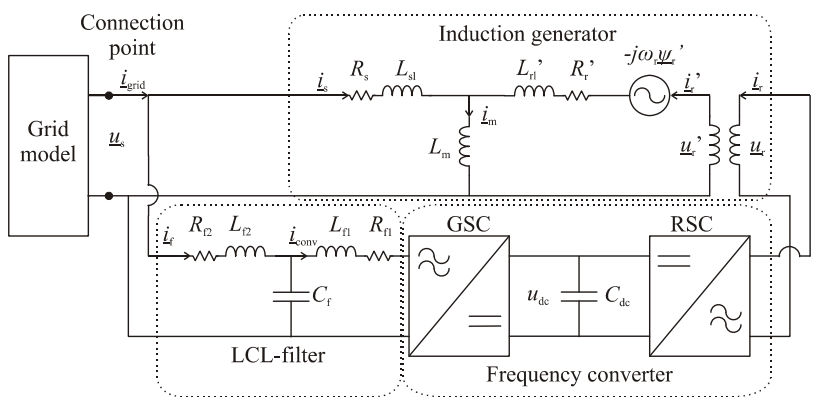

Fig. 2. Equivalent circuit of the DFIG.

The parameters of the generator, DC-link capacitor and LCL-filter are depicted in Table I. Both RSC and GSC are assumed to operate in linear modulation area. In other words, the over modulation option is not taken into account in this work. In addition, both converters are assumed to execute their voltage reference ideally i.e., the switching performance is not modelled in order to reduce simulation time.

Table I. - Parameters of DFIG system.

\begin{tabular}{|l|l|l|l|}
\hline Parameter & \multicolumn{1}{|c|}{ Value } & \multicolumn{1}{c|}{ Parameter } & \multicolumn{1}{c|}{ Value } \\
\hline$P_{\mathrm{n}}$ & $1700 \mathrm{~kW}$ & $L_{\mathrm{m}}$ & $3.8 \mathrm{mH}$ \\
\hline$u_{\mathrm{s} \_} 11$ & $690 \mathrm{~V}$ & $\begin{array}{l}\text { Turns ratio } \\
N_{\mathrm{r}} / N_{\mathrm{s}}\end{array}$ & 2.73 \\
\hline$R_{\mathrm{S}}$ & $0.0027 \Omega$ & Pole pairs & 2 \\
\hline$L_{\mathrm{s}}$ & $0.089 \mathrm{mH}$ & $u_{\mathrm{dc}}^{\text {ref }}$ & $1100 \mathrm{~V}$ \\
\hline$R_{\mathrm{r}}$ & $0.0026 \Omega$ & $C_{\mathrm{dc}}$ & $22 \mathrm{mF}$ \\
\hline$L_{\mathrm{r}}$ & $0.092 \mathrm{mH}$ & $L_{\mathrm{f} 1}$ & $190 \mu \mathrm{H}$ \\
\hline$R_{\mathrm{f} 1}$ & $15 \mathrm{~m} \Omega$ & $L_{\mathrm{f} 2}$ & $125 \mu \mathrm{H}$ \\
\hline$R_{\mathrm{f} 2}$ & $5 \mathrm{~m} \Omega$ & $C_{\mathrm{f}}$ & $70 \mu \mathrm{F}$ \\
\hline
\end{tabular}


The grid model is presented in Fig. 3. The grid model consists of step up transformer to $20 \mathrm{kV}$, wires modelled with $\pi$-model, passive load and voltage source.

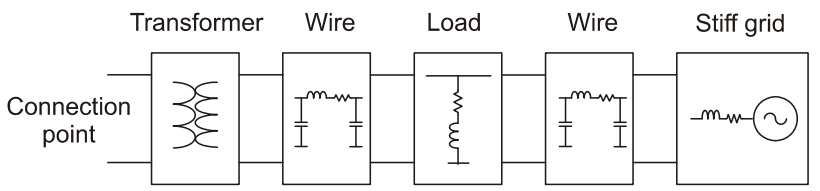

Fig. 3. Grid model.

\section{Control system}

The control system of the wind turbine is divided into two parts. The control system of the RSC adjusts the speed of the wind turbine. In addition, it controls the reactive power exchange with the grid. The GSC maintains constant DC-link voltage and injects reactive current into the network during grid voltage dip.

\section{A. Control system of GSC}

The GSC control is done in the reference frame oriented to the positive sequence of the connection point voltage. The positive sequence component of the voltage is extracted using dual second order generalized integratorfrequency-locked loop (DSOGI FLL), Fig 4. [7][8] In brief, DSOGI is a bandpass filter. The outputs are $v_{\alpha}$ ' and $v_{\beta}$ ' which are the filtered versions of the grid voltage components in stationary reference frame as well as $q v_{\alpha}$, and $q v_{\beta}$ ' which are inquadrature versions of $v_{\alpha}$ ' and $v_{\beta}$, respectively. The output signals are used to calculate positive and negative sequence (PNS) components of the grid voltage. The PNS components can be estimated very accurately as long as the filter resonance frequency $\omega$ ' corresponds to the grid frequency. However, the grid frequency is not constant. The FLL is used to modify the filter resonance frequency to grid frequency. Thus, the DSOGI-FLL is a filter adapted to grid frequency which outputs can be used to detect the PNS components of the grid voltage. More detailed discussion on DSOGI-FLL can be found in references [7][8].

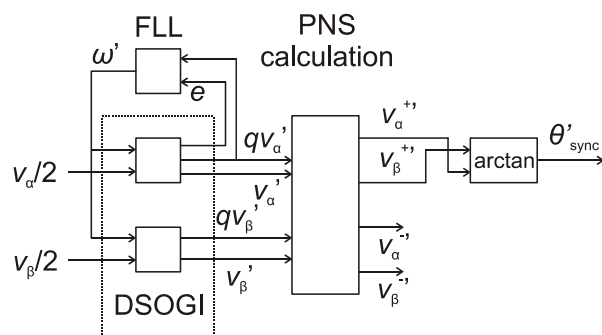

Fig. 4. Schematic diagram of the DSOGI-FLL.

The control system of the GSC is illustrated in Fig. 5. The fast inner loop controls the converter current $\underline{i}_{\text {conv }}$. The aim of the DC-link voltage controller is to keep constant DC-link voltage, thereby ensuring the active power balance between RSC and GSC. The output of the DC-link voltage controller is the reference of the converter current $\mathrm{x}$-component $i_{\text {conv, } \mathrm{x}} *$. In normal operation, the reference of converter current $y$ component $i_{\text {conv,y }}{ }^{*}$ is set to zero. However, during a network voltage dip, the current reference is increased in order to inject reactive power into the grid. The reference is calculated so that the converter current capacity is fully utilized.

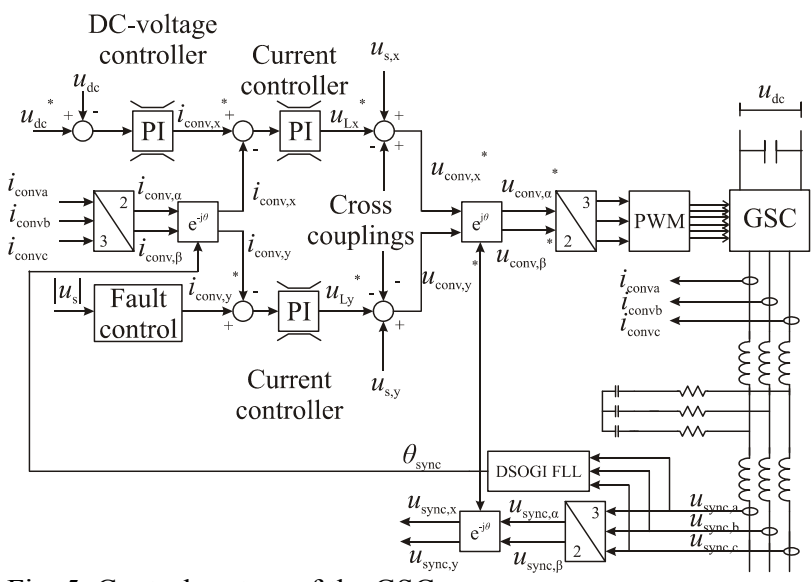

Fig. 5. Control system of the GSC.

\section{B. Control system of RSC}

The control system of the RSC is illustrated in Fig. 6. The control is based on vector control in a reference frame that is oriented to the estimated positive sequence of the stator flux linkage. The stator flux linkage is first calculated from the measured stator voltages and currents. Then, the PNS components of the stator flux linkage are estimated using DSOGI-FLL.

The RSC is controlled to extract maximum power from the wind by optimizing the ratio between blade tip speed and wind speed. The output of the speed controller is the reference for the torque. The torque controller gives the reference value for the rotor current $y$-component. The reactive power controller enables the control of reactive power exchange with the grid. The controller gives the reference for the rotor current $\mathrm{x}$-component. Cross coupling terms are added to the output of the current controller.

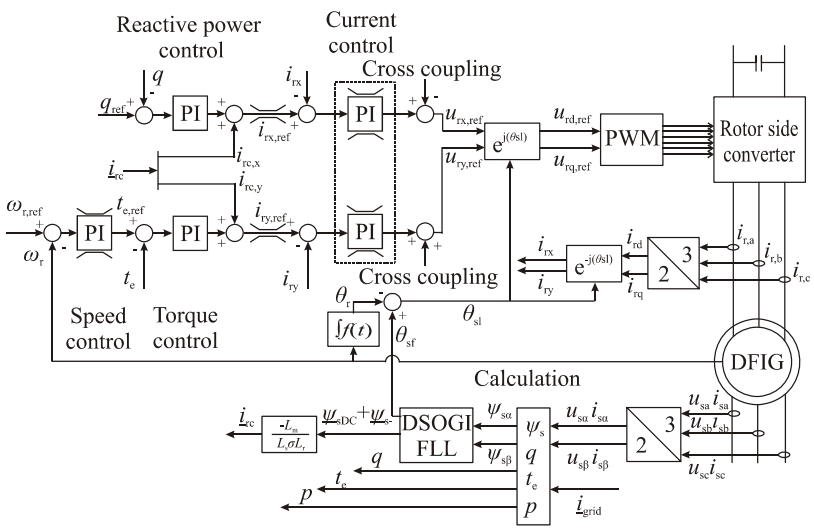

Fig. 6. Control system of the RSC.

\section{Transient flux compensation control}

The DSOGI-FLL is used to calculate the DC and negative sequence components from the stator flux linkage. The sum of these fluxes is called a transient flux. The rotor and stator flux linkage is defined as follows:

$\underline{\psi}_{\mathrm{s}}=L_{\mathrm{s}} \underline{i}_{\mathrm{s}}+L_{\mathrm{m}} \underline{i}_{\mathrm{r}}$ 
$\underline{\psi}_{\mathrm{r}}=L_{\mathrm{r}} \underline{i}_{\mathrm{r}}+L_{\mathrm{m}} \underline{i}_{\mathrm{s}}$

The rotor flux linkage can be expressed using Equations (1) and (2):

$\underline{\psi}_{\mathrm{r}}=\frac{L_{\mathrm{m}}}{L_{\mathrm{s}}} \underline{\psi}_{\mathrm{s}}+\frac{L_{\mathrm{r}}}{L_{\mathrm{s}}} \underline{i}_{\mathrm{r}}-\frac{L_{\mathrm{m}}^{2}}{L_{\mathrm{s}}} \underline{i}_{\mathrm{r}}=\frac{L_{\mathrm{m}}}{L_{\mathrm{s}}} \underline{\psi}_{\mathrm{s}}+\sigma L_{\mathrm{r}} \underline{i}_{\mathrm{r}}$

The transient flux is compensated by adding current components that oppose the transient flux. The current is achieved using Equation (3) and setting $\underline{\psi}_{\mathrm{r}}=0$ : [6]

$\underline{i}_{\mathrm{rc}}=-\frac{L_{\mathrm{m}}}{L_{\mathrm{s}} \sigma L_{\mathrm{r}}}\left(\psi_{\mathrm{sDC}}+\underline{\psi}_{\mathrm{s}-}\right)$

The idea behind the FRT concept that uses transient flux compensation control is to first cancel the transient flux in order to minimize its effect on the rotor and then feed the reactive power to the grid. Thus, the transient flux compensation current is prioritized. After transient flux removal all current capacity of RSC can be utilized.

\section{Simulation results}

Three-phase symmetrical short-circuit is assumed to occur in transmission network. This is modelled as a voltage dip of $25 \%$ of nominal the voltage in the stiff network in Fig. 3. The voltage dip lasts $300 \mathrm{~ms}$. The slip is $-23 \%$ in the beginning of the fault.

\section{A. Fault ride through without transient flux compensation}

The fault ride through strategy used in this study utilizes active crowbar protection. Crowbar is activated if the measured rotor current increases higher than the current feeding capability of RSC which is sized to be $900 \mathrm{~A} \mathrm{rms}$ (1270A peak value) in this case [9]. When the crowbar is connected to the rotor circuit the RSC is disconnected. During the crowbar connection the operation of the DFIG is not controllable. After the current is decreased so much that RSC can handle it the crowbar is deactivated and the $\mathrm{RSC}$ is connected back in operation. Since voltage dip is very deep, the reactive current is prioritized, see Fig. 1b, and the active current component is set to zero. From the beginning of the voltage dip also the GSC starts to feed reactive power to the grid in voltage support purposes. The amount of reactive power is determined by the current capability of GSC which in this case is $600 \mathrm{~A} \mathrm{rms}$ [10]. The grid phase voltages are shown in Fig. 7a. As mentioned above, the transient flux appears as a result of a voltage dip. The transient flux is shown in Fig. 8a in stator flux reference frame. It can be noticed that the decay of the flux is quite slow and that the transient flux doesn't decrease to zero even during a whole fault period.

The voltage of the rotor circuit is depicted in Fig. 9a. The high frequency oscillations on the rotor circuit voltage are due to the appearance of the transient flux. Transient flux also causes distortion to the rotor currents, Fig. 10a. The $\mathrm{y}$ - and $\mathrm{x}$-component of the rotor current in stator flux reference frame and their control references are expressed in Figs. 11a and 12a, respectively. Since the reactive power is prioritized the reference of the $\mathrm{x}$ component is increased and the reference of y-component is set to zero. However, the measured currents don't reach the references exactly since the presence of transient flux causes uncontrolled oscillations to the currents around the references. Due to the oscillations in measured currents the reference value of the current $\mathrm{x}$ component is set to be lower (i.e. 1120 A) than the current capacity of the RSC (i.e. $1270 \mathrm{~A}$ ). If the reference is set to $1270 \mathrm{~A}$, the measured currents would be temporarily higher than the limit due to the oscillations. That would, in turn, activate the crowbar protection continually which is undesirable from the voltage support viewpoint.

Since the y-component of the RSC current is set to zero the active power oscillates close to zero, Fig. 13a. The reactive power is shown in Fig. 14a. The negative value of the reactive power means that the reactive power is fed to the grid. Both RSC and GSC participate in the reactive power injection. The grid current is shown in Fig. 15a. It can be noticed that there are fluctuations in the currents due to the transient flux during a fault.

\section{B. Fault ride through with transient flux compensation}

Next, the same simulation as above is made with transient flux compensation control. After the crowbar is deactivated the RSC can be controlled again and the transient flux compensation current is prioritized. The demagnetizing current effectively cancels the transient flux, as can be seen in Fig. 8b. The RSC feeds only reactive current after the transient flux has decayed. Since the transient flux is removed the voltages and the currents in the rotor circuit are no longer distorted, as depicted in Figs. 9b and 10b. Compared to the previous case, there are no oscillations in the rotor $\mathrm{y}$ - and $\mathrm{x}$ component currents which are presented in Figs. $11 \mathrm{~b}$ and $12 \mathrm{~b}$. This is due to the fact that after the transient flux is cancelled the currents of DFIG are controllable. Hence, the reference for $\mathrm{x}$-component current can be set to 1270 A without fear of reactivation of the crowbar. Thus, the reactive power injection is maximized. Since there are no oscillations on $y$ - and $x$-component currents the active- and reactive power show a much steadier performance, Figs. $13 \mathrm{~b}$ and $14 \mathrm{~b}$, respectively. The grid currents shown in Fig. $15 \mathrm{~b}$ are symmetrical which denotes improved power quality.

\section{Conclusion}

In this paper, the fault ride through of doubly fed induction generator is studied. The aim of the paper is to reveal how the compensation of transient flux enhances the performance of a DFIG wind turbine during a voltage dip. A comparison of two FRT strategies was made. The first FRT strategy uses only the active crowbar to protect the turbine and the second strategy uses transient flux compensation in addition to the crowbar. Simulations are carried out using Matlab/Simulink. Simulation results show that if the transient flux is compensated the DFIG show much steadier behaviour and the DFIG is controllable during a fault. Thus, it is possible to utilize the whole current capacity of the RSC for reactive power injection into the grid. This is an important aspect since the latest grid codes require reactive power injection into the grid during a voltage dip. 
a)

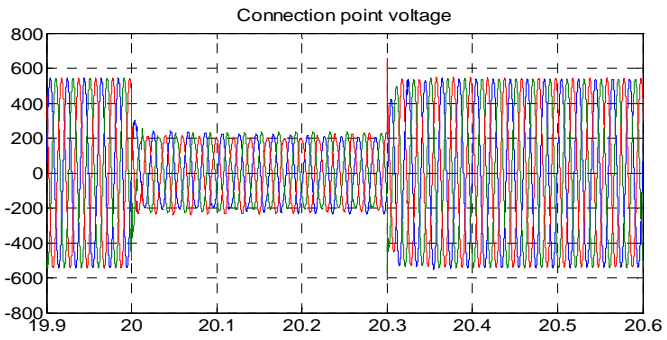

Fig. 7. Connection point voltages: a) without compensation, b) with compensation.
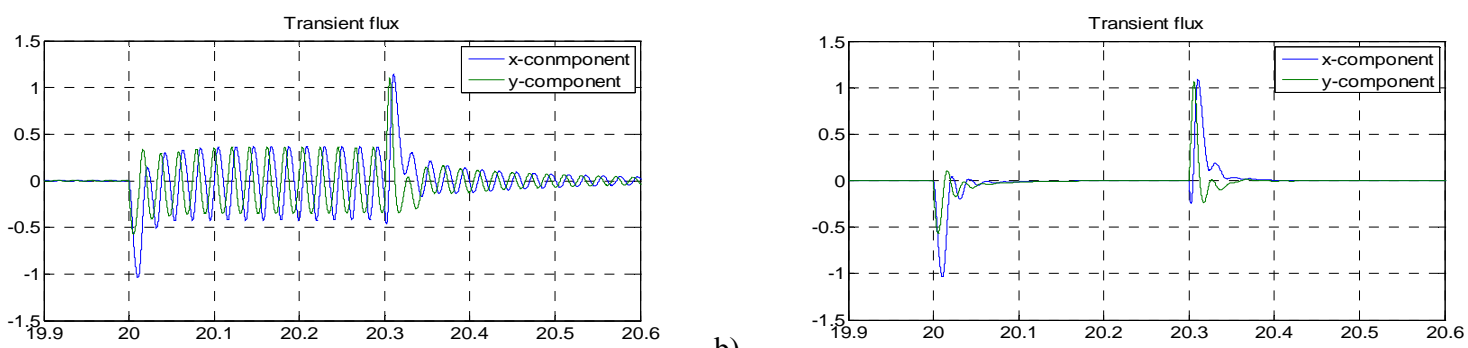

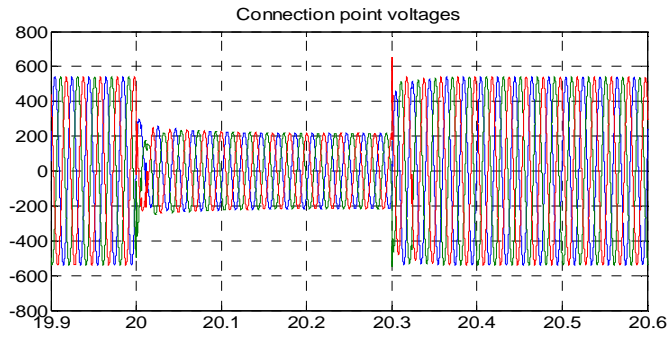

b) b)

a)

Fig. 8. Transient flux: a) without compensation, b) with compensation.

a)

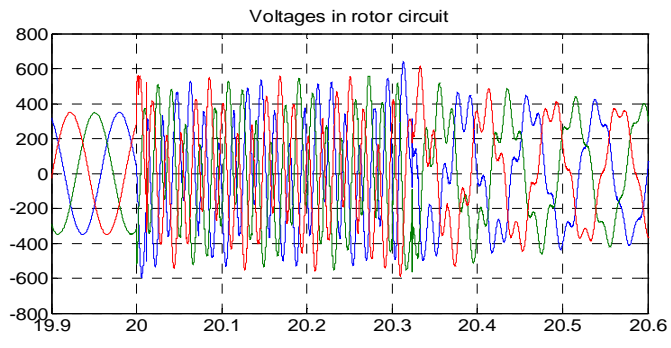

a)

b)
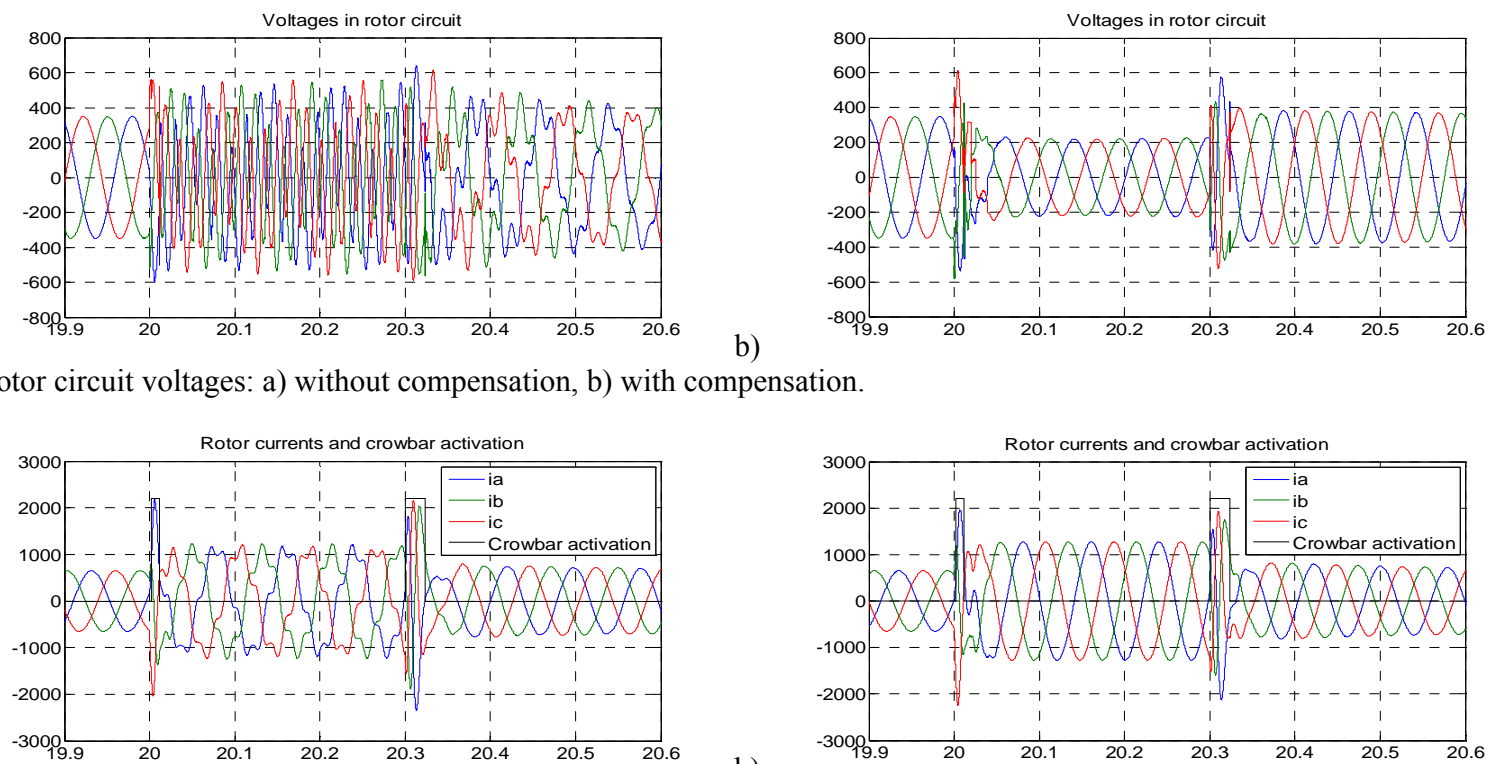

a)

Fig. 10. Rotor currents: a) without compensation, b) with compensation.

a)

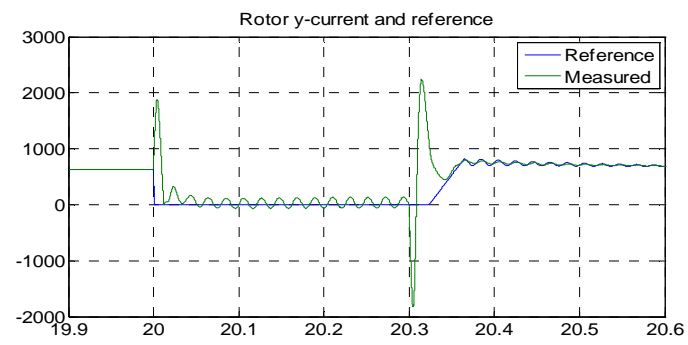

Fig. 11. Rotor current y-component and its reference: a) without compensation, b) with compensation.

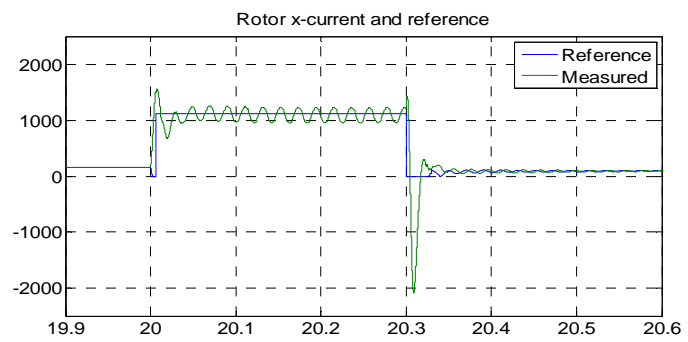

a)

Fig. 12. Rotor current $\mathrm{x}$-component and its reference: a) without compensation, b) with compensation.

b)

b)
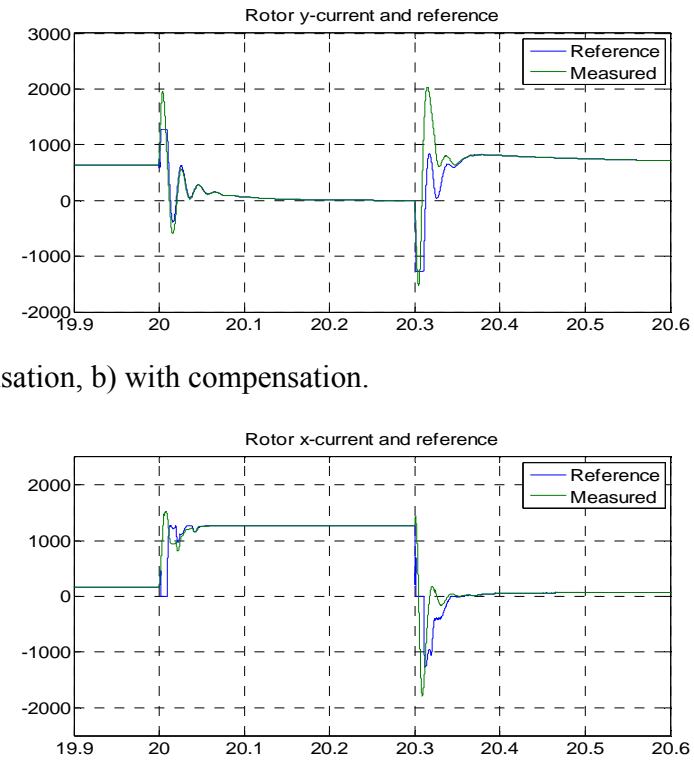
a)

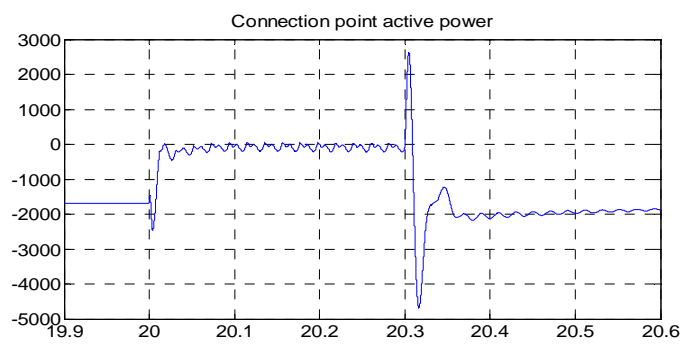

b)

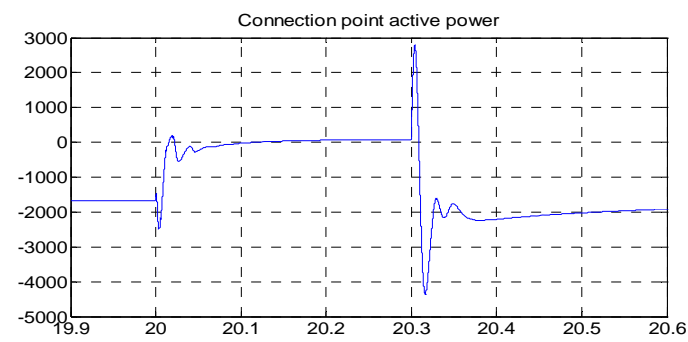

Fig. 13. Connection point active power: a) without compensation, b) with compensation.

a)

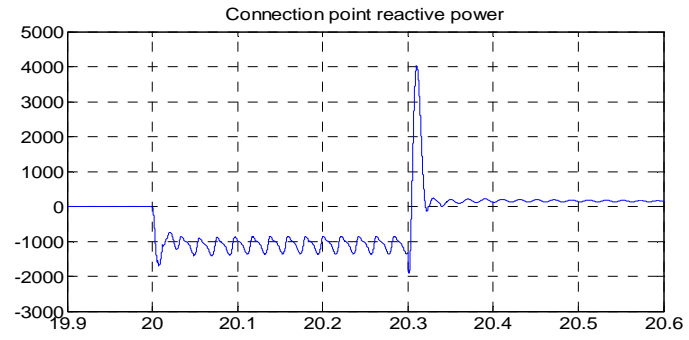

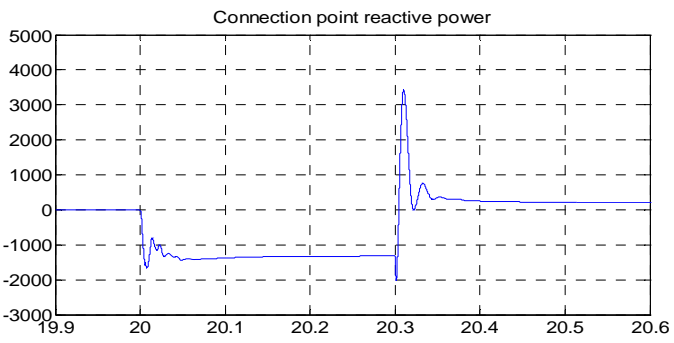

b)

Fig. 14. Connection point reactive power: a) without compensation, b) with compensation.

a)

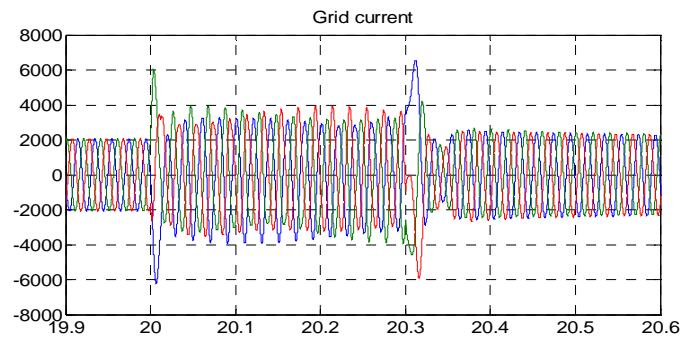

b)

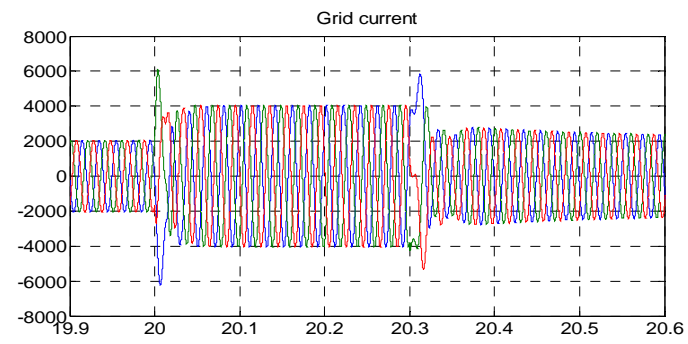

Fig. 15. Grid currents: a) without compensation, b) with compensation.

\section{Acknowledgement}

This work has been done within the demonstration project ADINE (Active Distribution Network) co-funded by the European Commission and the Sixth Framework Programme. The aim of the project is to develop new methods for active network management of a distribution network.

\section{References}

[1] World Wind Energy Association (WWEA) Website. October 2010. Available: http://www.wwindea.org/home/index.php

[2] E-ON Netz GmbH. April 2006, Grid Code -High and extra high voltage. [Online]. Available:

http://www.pvupscale.org/IMG/pdf/D4_2_DE_annex_A3_EON_HV_grid connection_requirements ENENARHS2006.

[3] J. Lopez, P. Sanchis, X. Roboam and L. Marroyo, "Dynamic Behavior of the Doubly Fed Induction Generator During Three-Phase Voltage Dips", IEEE Transactions on Energy Conversion, Vol. 22, No.3, September 2007, pp. 709-717.
[4] I. Erlich, M. Wilch and C. Feltes, "Reactive Power Generation by DFIG Based Wind Farms with AC Grid Connection", Power Electronics and Applications, September 2007, Aalborg, Denmark, pp. 1-10.

[5] D. Xiang, L. Ran, P.J. Tavner and S. Yang, "Control of a Doubly Fed Induction Generator in a Wind Turbine During Grid Fault Ride-Through", IEEE Transactions on Energy Conversion, Vol. 21, No. 3, September 2006, pp. 652-662.

[6] J. Lopez, E. Gubia, E. Olea, J. Ruiz and L. Marroyo, "Ride Through of Wind Turbines With Doubly Fed Induction Generator Under Symmetrical Voltage Dips", IEEE Transactions on Industrial Electronics, Vol. 56, No. 10, October 2009, pp. 4246-4254.

[7] F.K.A. Lima, A. Luna, P. Rodriguez, E.H. Watanabe and F. Blaabjerg, "Rotor Voltage Dynamics in the Doubly Fed Induction Generator During Grid Faults", IEEE Transactions on Power Electronics, Vol. 25, No. 1, January 2010, pp. 118-130.

[8] P. Rodriguez, A. Luna, M. Ciobotaru, R. Teodorescu and F. Blaabjerg, "Advanced Grid Synchronization Systems for Power Converters under Unbalanced and Distorted Operating Conditions", in proc. IEEE Industrial Electronics Conference, November 2006, pp. 5173-5178.

[9] Westcode website. January 2011. Available: http://www.westcode.com/t1200ta.pdf

[10] Westcode website: January 2011. Avalable: http://www.westcode.com/t0600ta.pdf 